\title{
Study protocol of a double-blind randomised placebo-controlled trial on the effect of a multispecies probiotic on the incidence of antibiotic-associated diarrhoea in persons with spinal cord injury
}

\author{
W. X. M. Faber ${ }^{1}$ J. Nachtegaal ${ }^{2}$ J. M. Stolwijk-Swuste ${ }^{3}$ W. J. Achterberg-Warmer ${ }^{4}$ • C. J. M. Koning ${ }^{5}$. \\ I. Besseling-van der Vaart ${ }^{5}$. C. A. M. van Bennekom ${ }^{1,2}$
}

Received: 21 May 2019 / Revised: 20 September 2019 / Accepted: 2 October 2019 / Published online: 11 November 2019

(c) The Author(s), under exclusive licence to International Spinal Cord Society 2019

\begin{abstract}
Study design Multi-centre, double-blind randomised placebo-controlled study.

Objective To investigate whether the use of a multispecies probiotic can prevent antibiotic-associated diarrhoea in people with spinal cord injury (SCI).

Setting Three Dutch SCI rehabilitation centres.

Methods Fifty-six people aged 18-75 years with SCI during inpatient rehabilitation, who require antibiotics, will be given probiotics or placebo randomly assigned (T0). After cessation of the antibiotics (T1), the participants will use probiotics/ placebo for 3 more weeks (T2). Defaecation, assessed by the Bristol Stool Scale, and bowel management will be monitored daily until 2 weeks after cessation of probiotics/placebo intake (T3). Also, the degree of nausea and information on quality of life will be collected at T0, T1, T2 and T3.

Main outcome measures The difference between the incidence of antibiotic-associated diarrhoea between people with SCI using probiotics compared to those using a placebo at the moment the antibiotics stops, the probiotics stops and two weeks thereafter.
\end{abstract}

Secondary outcome measures The time to reach effective bowel management, degree of nausea and quality of life.

Registration The Dutch Trial Register- NTR 5831.

\section{Introduction}

Neurogenic bowel dysfunction is one of the most disabling impairments caused by spinal cord injury (SCI). It is defined as a colonic dysfunction resulting from a lack of central

W. X. M. Faber

w.faber@heliomare.nl

1 Heliomare Rehabilitation Center, Wijk aan Zee, The Netherlands

2 Department of Research \& Development, Heliomare Rehabilitation Center, Wijk aan Zee, The Netherlands

3 Center of Excellence for Rehabilitation Medicine, Brain Center Rudolf Magnus, University Medical Center Utrecht and De Hoogstraat Rehabilitation, Utrecht University, Utrecht, the Netherlands

4 Amsterdam Rehabilitation Research Center, Reade, the Netherlands

5 Winclove Probiotics B.V, Amsterdam, The Netherlands nervous control [1]. In a survey among 1334 people with SCI, 39\% reported constipation, 36\% haemorrhoids and $31 \%$ abdominal distension [2]. Other possible consequences are diarrhoea and incontinence [3].

Bowel dysfunction following SCI has a huge impact on quality of life (QoL) [2,3]. In people with faecal incontinence, $62 \%$ reported a negative effect on QoL, compared with $8 \%$ in controls $[1,4]$. Bowel management can reduce the impact on QoL and prevent faecal incontinence and constipation [2]. Bowel management is influenced by many factors such as the use of digital anal stimulation, diet or pharmacological treatment [1]. In acute SCI, achieving effective bowel management is a multifaceted and time-consuming process [2]. It is an important component of the rehabilitation period and remains a lifelong challenge.

Other frequently observed secondary conditions in SCI are neurogenic bladder dysfunction, respiratory and skin problems [5]. People with SCI are therefore at risk of developing infections $[6,7]$ that often require antibiotic 
treatment. One of the side effects of antibiotic use is dysbiosis of intestinal microbiota, which can result in antibiotic-associated diarrhoea (AAD) [8]. AAD is defined as three or more liquid stools (Bristol Stool Scale (BSS) 5, 6 or 7) per day for 3 or more days [9-11]. In 2017 a paper was published on the use of antibiotics and the prevalence of AAD in people with SCI [12]. In this study 22\% of 215 people with SCI suffered from AAD.

AAD might have a negative influence on the rehabilitation process. For example, frequent periods of diarrhoea often result in a delay in achieving effective bowel management. Furthermore, it leads to feelings of general discomfort, other complications such as pressure ulcers, and people might be less active [13]. All this can result in even more complications [7, 14].

Several systematic reviews and meta-analyses have shown probiotics to be beneficial in preventing AAD in people with various diagnoses, such as irritable bowel syndrome and paediatric AAD [15, 16]. In 2014 a randomised controlled trial was published on the effect of probiotics on AAD in people with SCI. This study indicated that probiotics could reduce the incidence of AAD in hospitalised people with SCI. The authors advised a randomised placebo-controlled trial to confirm this success [9]. In 2015 Wong et al. published a protocol for a systematic review on the effectiveness of probiotics in preventing and treating AAD in people with SCI [17]. They concluded that the effectiveness of the current use of probiotics to prevent and treat AAD remains inconclusive.

In conclusion, there is much to gain for people with SCI who need antibiotic treatment and are therefore at risk of AAD and trials on the effect of probiotics in this population are scarce. Therefore, in this study, we will investigate the effect of a specifically designed multispecies probiotic on preventing AAD in people with SCI who are treated with antibiotics in a placebo-controlled trial. We will also examine whether the use of probiotics in this population, shortens the time needed to achieve effective bowel management, prevents nausea and improves QoL.

\section{Objectives}

The primary objective is to test the hypothesis that people with SCI, using antibiotics supplemented with a multispecies probiotic have less AAD compared with people with SCI, using antibiotics supplemented with placebo. The secondary objectives are to investigate whether intake of a multispecies probiotic in persons with SCI who use antibiotics: 1. ensures that effective bowel management is achieved faster compared with placebo 2 . decreases nausea and 3. increases QoL compared with placebo.

\section{Methods}

\section{Trial design and study setting}

This double-blind randomised placebo-controlled study will investigate the effect of a multispecies probiotic on the development of AAD. The design of the study is shown in Fig. 1. The study will be performed at three rehabilitation centres in the Netherlands: Heliomare at Wijk aan Zee, Reade at Amsterdam and De Hoogstraat at Utrecht.

\section{Eligibility criteria}

All people (aged 18-75 years) with an SCI who are admitted to one of the three inpatient rehabilitation centres will be informed on the study and invited to participate. They are asked shortly after their admission, before they might develop an infection and will need antibiotics, so they will have time to think about their possible participation. If they decide to participate, their informed consent will be registered in the electronic patient record. People with informed consent, who develop an infection and still meet the inclusion criteria, will be enroled in the study when starting antibiotic treatment. People meeting one or more of the following conditions are excluded from participation:

Known gastro-intestinal diseases;

Abdominal surgery within a year prior to enrolment to the study;

Previous or ongoing radiotherapy or chemotherapy;

Severe autoimmune diseases such as systemic lupus erythematosus;

Severe acute pancreatitis, multiple organ failure or sepsis; Enteral feeding, except for nasogastric feeding;

Excessive alcohol intake ( $>15$ units per week);

Planned or actual pregnancy or lactation;

Use of probiotics during or in the month prior to the study;

Use of antibiotics in the 2 weeks prior to the study;

More than one antibiotic treatment in the 6 months prior to the study;

Previous participation in this study;

Use of antibiotics for longer than 10 days;

Use of flucloxacillin or nitrofurantoin (as these antibiotics are not associated with ADD).

\section{Sample size}

Data on the prevalence of AAD in persons with SCI are limited. The study of Wong et al. among people with SCI showed an incidence of AAD of 55\% in the control group, while an incidence of $17 \%$ was observed in the probiotics 
Fig. 1 Flow chart of the study design

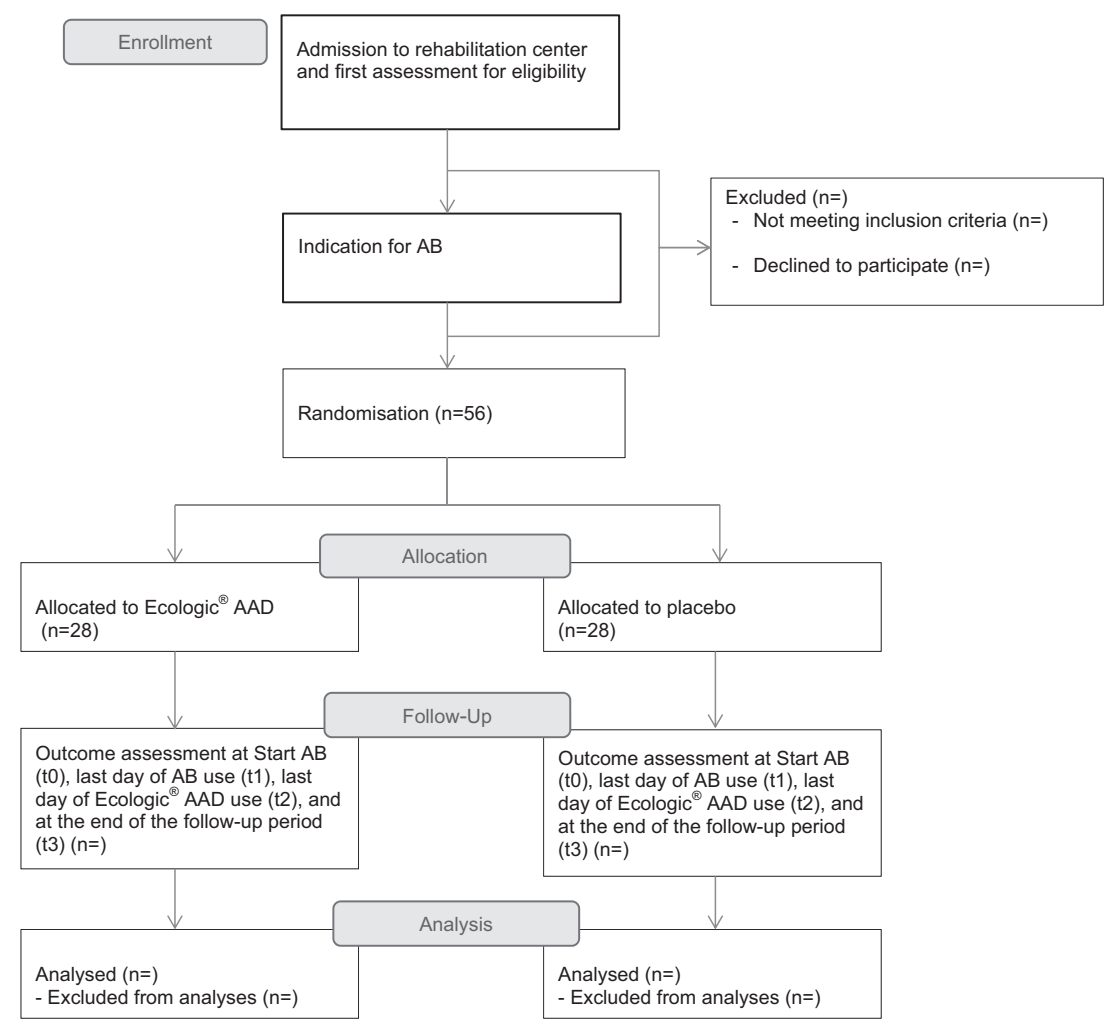

group [9]. Based on these results, we estimate that a sample size of 28 per arm is needed to show a $35 \%$ difference in the proportion of participants developing AAD $(60 \%$ in the control group and $25 \%$ in the multispecies probiotic group) with a statistical power of $80 \%$ and at a significance level of $5 \%$.

\section{Allocation and blinding}

The trial will be performed double-blinded in three rehabilitation centres. The randomisation will be performed centrally by an independent department and stratified by rehabilitation centre. Blocked randomisation will be used to ensure a good balance of participant characteristics in each group and all study products will be sequentially numbered. Coded study products will be given to the researchers. Everyone involved in the study is blinded to the intervention until the study is completed. At the end of the study, the independent department will divide the participants into two blinded groups. Hence, the researchers performing the statistical analyses will not know, which group the intervention group is. After performing the analyses, code numbers will be opened by the coordinating and principal investigators. The principal investigator receives sealed envelopes with the allocation of each number, ensuring that if a medical problem occurs for which treatment allocation is needed, the code can always be broken. No participant information will be shared with the company performing the randomisation.

\section{Intervention}

When put on a course of antibiotics, the participant will be enroled in the study and be randomly assigned to receive either a multispecies probiotic or a placebo. The multispecies probiotic or placebo is orally taken, twice daily and $2 \mathrm{~h}$ before or after intake of antibiotics. After cessation of antibiotic treatment, the participant will continue to use the probiotics/placebo for a further 3 weeks (Fig. 2). To improve adherence to the intervention, the multispecies probiotic or placebo is administered by the nursing staff. Possible reasons for discontinuing the intervention will be participant withdrawal or worsening disease. The reason for drop-out will be registered. Participants who receive less than $75 \%$ of the recommended dose of multispecies probiotic or placebo will be considered as non-compliant.

In this study we will use Ecologic ${ }^{\circledR}$ AAD. This multispecies probiotic has been specifically developed to prevent antibiotic-associated disturbances of the intestinal microbiota. The product has shown to reduce the incidence of diarrhoea [18, 19]. This multispecies probiotic has a recommended dosage of $5 \mathrm{~g}$ twice daily, with a total viable cell count of $1 \times 10^{10}$ colony forming unit/day. This dosage is based on prior human studies in healthy volunteers and general surgery patients showing a health benefit without adverse reactions [18-22]. The multispecies probiotic has been used in several clinical studies in different 
Fig. 2 Schedule of data collection

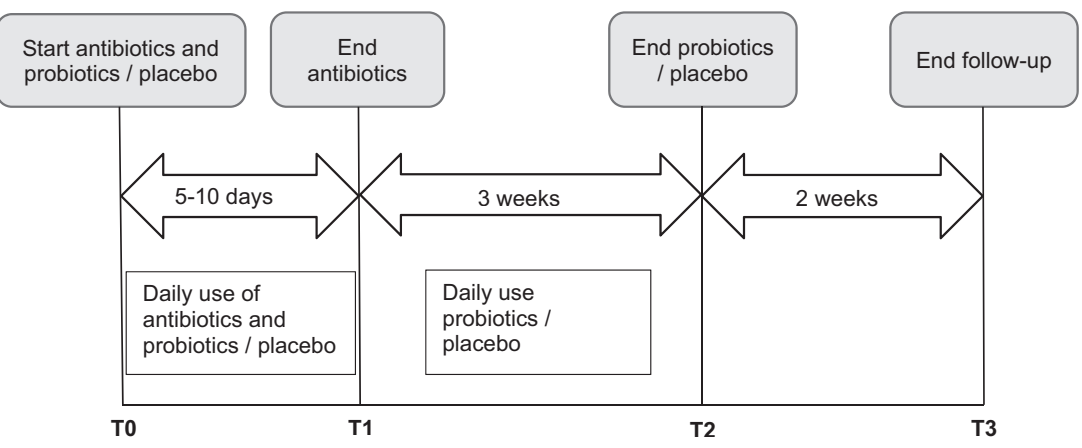

populations, without any adverse effects. It is commercially available in several countries and no serious adverse effects have been reported [18, 21,23]. This probiotic food supplement consists of the following nine probiotic bacterial strains: Bifidobacterium bifidum W23, Bifidobacterium lactis W51, Enterococcus faecium W54, Lactobacillus acidophilus W37, Lactobacillus acidophilus W55, Lactobacillus paracasei W20, Lactobacillus plantarum W62, Lactobacillus rhamnosus W71 and Lactobacillus salivarius W24. The product also contains maize starch, maltodextrin, fructo-oligosaccharides P6, maize dextrin P9, potassium chloride, hydrolysed rice protein, magnesium sulphate, amylase and manganese sulphate. A placebo will be used as a comparator. The placebo product is indistinguishable in colour, smell and taste from the active formulation, and will have the same composition but without the live bacteria, fructo-oligosaccharides and maize dextrin P9.

\section{Data collection and management}

Data will be collected when the treatment with antibiotics starts (T0), when the use of antibiotics stops (T1), when the use of probiotic/placebo stops (T2) and 2 weeks after the probiotic/placebo is stopped (T3) (Fig. 2). In each centre, data will be collected by a research assistant. To promote data quality, the assessors are instructed how to collect the data. All participants will receive a study identification number. The study identification number and baseline data will be stored at a central database and printed. Outcome data will be both added to the electronic database and on paper. The database is password protected; paper copies are stored in a locked locker. Both versions will be accessible to the involved researchers only. Data entry and validity will be double checked randomly by two investigators. A data monitoring committee is not required, as the risk of harm is classified as negligible. The study is approved by the Medical Ethics Committee of Amsterdam UMC. We have started collecting data in 2018 and data collecting is expected to be completed in 2021.
Adverse events and serious adverse events (SAE)

Any adverse event that occurs within the study will be registered by the principle investigators of the three centres and notified to the coordinating researcher. In case of an SAE the ethics committee will be notified as well. When unexpected circumstances require changes of the protocol, modifications will be reported at the Dutch trial register site and if relevant, reported to the ethical committee, study personnel and manufacturer of the product. In case of a SAE for which treatment allocation is needed, the code can be broken at all time.

\section{Outcomes, characteristics and descriptive variables}

An overview of the primary and secondary outcomes, descriptive variables and timing of the data collection is shown in Table 1.

\section{Primary outcome}

The primary outcome will be the difference between the incidence of AAD between people with SCI using a multispecies probiotic compared with those using a placebo, which will be determined using the BSS at T1, T2 and T3 [24]. The BSS has been shown to be valid and reliable in persons with SCI [9]. The consistency of stool is scored on a scale of 1 to 7, where 5, 6 and 7 indicate a liquid stool. In addition, the frequency of defaecation will be recorded to monitor the defaecation pattern. AAD is defined as three or more liquid stools (BSS score 5, 6 or 7) per day for 3 or more days. The BSS is filled out daily. At T1 (end of antibiotic intake) the incidence (yes/no) of AAD in the period from $\mathrm{T} 0$ to $\mathrm{T} 1$ is determined. At $\mathrm{T} 2$ (end of probiotic/placebo) the incidence since $\mathrm{T} 1$ and at $\mathrm{T} 3$ (follow-up) since $\mathrm{T} 2$.

\section{Secondary outcomes}

The secondary outcomes will be time to reach effective bowel management, degree of nausea and QoL. Effective 
Table 1 List of outcome measures \& answer categories

\begin{tabular}{|c|c|c|c|c|c|c|c|}
\hline \multirow[t]{2}{*}{ Construct } & \multicolumn{5}{|c|}{ Timing } & \multirow[t]{2}{*}{ Measure } & \multirow[t]{2}{*}{ Definition } \\
\hline & Daily & T0 & $\mathrm{T} 1$ & $\mathrm{~T} 2$ & T3 & & \\
\hline \multicolumn{8}{|l|}{ Primary outcome } \\
\hline Incidence of AAD & $\mathrm{X}$ & & $\mathrm{X}$ & & & $\begin{array}{l}\text { BSS and frequency of } \\
\text { defaecation }\end{array}$ & $\begin{array}{l}\text { Yes/no } \\
\text { AAD: } \geq 3 \text { or more liquid stools (BSS chart } 5,6 \text {, or } 7 \text { ) per day, for } 3 \text { or more days }\end{array}$ \\
\hline \multicolumn{8}{|l|}{ Secondary outcomes } \\
\hline Effective bowel management & & $\mathrm{X}$ & $\mathrm{X}$ & $\mathrm{X}$ & $\mathrm{X}$ & & $\begin{array}{l}\text { Yes/no } \\
\text { Effective bowel management: stable bowel medication scheme without incontinence } \\
\text { or obstipation }\end{array}$ \\
\hline Faecal incontinence & & $\mathrm{X}$ & $\mathrm{X}$ & $\mathrm{X}$ & $\mathrm{X}$ & $\begin{array}{l}\text { ISCoS dataset bowel } \\
\text { management }\end{array}$ & $\begin{array}{l}\text { Yes/no } \\
\text { Faecal incontinence } \\
\text { Frequency of faecal incontinence during the past } 4 \text { weeks (T0) or since the preceding } \\
\text { measurement moment (T1-T3). Answer categories are (a) } \geq 2 \text { times a day (b) once a } \\
\text { day (c) } 1-6 \text { times a week (d) never }\end{array}$ \\
\hline Obstipation & & $\mathrm{X}$ & $\mathrm{X}$ & $\mathrm{X}$ & $\mathrm{X}$ & $\begin{array}{l}\text { ISCoS dataset bowel } \\
\text { management }\end{array}$ & $\begin{array}{l}\text { Yes/no } \\
\text { Obstipation: defaecation frequency of twice a week or less } \\
\text { Frequency of defaecation during the past } 4 \text { weeks (T0) or since the preceding } \\
\text { measurement moment (T1-T3). Answer categories are (a) } \geq 3 \text { times per day (b) twice } \\
\text { daily (c) once daily (d) not daily but more than twice every week (e) twice every week } \\
\text { (f) once every week (g) less than once every week but at least once within the last } \\
4 \text { weeks (h) no defaecation within the last } 4 \text { weeks (i) never }\end{array}$ \\
\hline Defaecation method & & $\mathrm{X}$ & $\mathrm{X}$ & $\mathrm{X}$ & $\mathrm{X}$ & $\begin{array}{l}\text { ISCoS dataset bowel } \\
\text { management }\end{array}$ & $\begin{array}{l}\text { Within the last } 4 \text { weeks (T0) or since the preceding measurement moment (T1-T3) (a) } \\
\text { normal defaecation (b)straining/bearing down (c) digital anorectal stimulation (d) } \\
\text { suppositories (e) digital evacuation (f) mini enema (g) enema (h) colostomy (i) SARS } \\
\text { (j) other }\end{array}$ \\
\hline Stable bowel medication scheme & & $\mathrm{X}$ & $\mathrm{X}$ & $\mathrm{X}$ & $\mathrm{X}$ & Electronic patient record & $\begin{array}{l}\text { Yes/no } \\
\text { Changes in bowel medication. Medication scheme is considered stable when there are } \\
\text { no chances in prescription during the past week (T0) or since the preceding } \\
\text { measurement moment (T1-T3) }\end{array}$ \\
\hline Nausea & & $\mathrm{X}$ & $\mathrm{X}$ & $\mathrm{X}$ & $\mathrm{X}$ & VAS & $\begin{array}{l}\text { Nausea during the past } 4 \text { weeks (T0) or since the preceding measurement moment } \\
\text { (T1-T3). Ranges from 'no nausea' to 'worst possible nausea'. Scored as distance in } \\
\mathrm{mm} \text { from 'no nausea' to patient mark }\end{array}$ \\
\hline \multicolumn{8}{|l|}{ Quality of life } \\
\hline General quality of life & & $\mathrm{X}$ & $\mathrm{X}$ & $\mathrm{X}$ & $\mathrm{X}$ & ISCoS dataset QoL & $\begin{array}{l}\text { How satisfied are you with your life as a whole? } \\
\text { Scores ranges from } 0 \text { (completely dissatisfied) to } 10 \text { (completely satisfied), or any } \\
\text { number in between }\end{array}$ \\
\hline Physical health & & $\mathrm{X}$ & $\mathrm{X}$ & $\mathrm{X}$ & $\mathrm{X}$ & ISCoS dataset QoL & $\begin{array}{l}\text { How satisfied are you with your physical health? } \\
\text { Scores ranges from } 0 \text { (completely dissatisfied) to } 10 \text { (completely satisfied), or any } \\
\text { number in between }\end{array}$ \\
\hline Psychological health & & $\mathrm{X}$ & $\mathrm{X}$ & $\mathrm{X}$ & $\mathrm{X}$ & ISCoS dataset QoL & $\begin{array}{l}\text { How satisfied are you with your psychological health? Scores ranges from } 0 \\
\text { (completely dissatisfied) to } 10 \text { (completely satisfied), or any number in between }\end{array}$ \\
\hline QoL compared with before SCI & & $\mathrm{X}$ & $\mathrm{X}$ & $\mathrm{X}$ & $\mathrm{X}$ & ISCoS dataset QoL & $\begin{array}{l}\text { How satisfied are you with your quality of life now, compared with your quality of life } \\
\text { before the SCI }\end{array}$ \\
\hline \multicolumn{8}{|l|}{ Participant and disease characteristics } \\
\hline Age & & $\mathrm{X}$ & & & & & In years \\
\hline Gender & & $\mathrm{X}$ & & & & & Male/female \\
\hline Neurological level of injury & & $\mathrm{X}$ & $\mathrm{X}$ & $\mathrm{X}$ & $\mathrm{X}$ & AIS & ASIA impairment Scale \\
\hline Time since injury & & $\mathrm{X}$ & & & & & \\
\hline \multicolumn{8}{|l|}{ Descriptive variables } \\
\hline Walking ability & & $\mathrm{X}$ & $\mathrm{X}$ & $\mathrm{X}$ & $\mathrm{X}$ & Hoffer & $\begin{array}{l}\text { Classification of walking ability (a) nonambulatory (b) therapeutic walker (c) } \\
\text { household walker (d) community walker }\end{array}$ \\
\hline $\begin{array}{l}\text { Bowel problems (not related } \\
\text { to SCI) }\end{array}$ & & $\mathrm{X}$ & & & & $\begin{array}{l}\text { ISCoS dataset bowel } \\
\text { management }\end{array}$ & $\begin{array}{l}\text { Gastro-intestinal or sphincter dysfunction, peri-anal problems, previous gastro- } \\
\text { intestinal surgical procedures }\end{array}$ \\
\hline Time needed to defecate & & $\mathrm{X}$ & $\mathrm{X}$ & $\mathrm{X}$ & $\mathrm{X}$ & & $\begin{array}{l}\text { Average time required for defaecation (a) } 0-30 \mathrm{~min} \text { (b) } 31-60 \mathrm{~min} \text { (c) } \geq 60 \mathrm{~min} \text { (d) } \\
\text { unknown }\end{array}$ \\
\hline Use of incontinence material & & $\mathrm{X}$ & $\mathrm{X}$ & $\mathrm{X}$ & $\mathrm{X}$ & & Need to wear pad or plug (within the last four weeks) (a) no (b) yes (c) unknown \\
\hline Defaecation method & & $\mathrm{X}$ & $\mathrm{X}$ & $\mathrm{X}$ & $\mathrm{X}$ & & $\begin{array}{l}\text { Within the last } 4 \text { weeks (T0) or since the preceding measurement moment (T1-T3) (a) } \\
\text { normal defaecation (b) straining/bearing down (c) digital anorectal stimulation (d) } \\
\text { suppositories (e) digital evacuation; (f) mini enema (g) enema (h) colostomy (i) SARS } \\
\text { (j) other (k) unknown }\end{array}$ \\
\hline Antibiotic use & & $\mathrm{X}$ & $\mathrm{X}$ & & & Electronic patient record & Type and duration of antibiotic use \\
\hline Medication use & & $\mathrm{X}$ & $\mathrm{X}$ & $\mathrm{X}$ & $\mathrm{X}$ & Electronic patient record & Medication affecting bowel function \\
\hline
\end{tabular}

bowel management is defined as a stable bowel management including a stable bowel medication scheme and evacuation method, without incontinence or obstipation. Bowel function and evacuation methods will be determined using the Dutch Dataset on Spinal Cord Injury Rehabilitation (DDSCIR) [25]. This is a standardised dataset for collecting information on persons with SCI and is used in all Dutch SCI rehabilitation centres. The DDSCIR includes the translated international SCI datasets on bowel function and QoL [26, 27]. Defaecation frequency will be registered in the DDSCIR. Defaecation frequency is defined as the number of defaecations during the past four weeks (T0), or since the last measurement (T1, T2 and T3). Ten categories are distinguished, varying from more than 3 times a day, to no defaecation during the past 4 weeks. At T0 we will score whether the participant has an effective bowel management 
during the past 4 weeks. At T1, T2 and T3 we will score whether the participant has an effective bowel management since the last measurement.

Degree of nausea will be measured with the Nausea Visual Analogue Scale. Participants will be asked to make a mark on a 10-cm-long line to score their feeling of nausea, ranging from 'No nausea' (0) to 'Worst possible nausea' [10]. The scale is scored by measuring the distance from 'No nausea' ( 0 ) to the participant's mark. This VAS method proved to be reliable and sensitive for assessing postoperative quantitative nausea intensity [28].

QoL in the DDSCIR is measured with the ISCoS QoL basic dataset [26], and is defined by four questions. General QoL (how satisfied are you with your life as a whole), physical health (how satisfied are you with your physical health), and psychological health (how satisfied are you with your psychological health), are rated on a scale from 0 to 10 . Zero corresponds to completely dissatisfied and 10 corresponds to completely satisfied. The last question determines how satisfied the person is with his QoL today, compared with his QoL before the SCI. Seven categories are defined: (1) much worse, (2) worse, (3) a little worse, (4) about the same, (5) a little better, (6) better and (7) much better. The four questions are analysed separately.

\section{Participant and disease characteristics}

The participant characteristics that will be registered are age, gender and time since injury.

The disease characteristics will be the SCI classification according to the American Spinal Injury Association (ASIA) [29].

\section{Descriptive variables}

Descriptive variables are bowel problems not related to the SCI, the method of defaecation, time needed to defaecate and use of incontinence material. All are determined using the DDSCIR (Table 1). Bowel problems (not related to the SCI) which are distinguished are any gastro-intestinal or sphincter dysfunction, peri-anal problems and previous gastro-intestinal surgical procedures. Furthermore, type and duration of antibiotic prescribed and use of medication affecting bowel function will be registered. Ambulatory status will be categorised by the Hoffer classification as nonambulatory, therapeutic, household and community [30]. Walking ability will be measured because of its potential influence on bowel function.

\section{Statistical methods}

Descriptive statistics will be used to describe the participant and disease characteristics of both groups. Analyses will be performed according the per protocol principle. Participants who received at least $75 \%$ of the recommended dose of multispecies probiotic or placebo will be included in the analyses. In addition, analyses according the intention-totreat principle will be performed. IBM SPSS Statistics version 23 will be used to analyse the data.

\section{Primary research question}

To answer the primary research question, differences in the presence of AAD between the probiotics group and the placebo group will be tested at $\mathrm{T} 1, \mathrm{~T} 2$ and $\mathrm{T} 3$ using logistic regression analyses. To estimate differences between groups over time, longitudinal regression analyses will be used. Odds ratios, 95\% confidence intervals $(95 \% \mathrm{CI})$, and $p$ values will be presented.

\section{Secondary research questions}

Differences in effective bowel management between both groups will be analysed at $\mathrm{T} 1, \mathrm{~T} 2$ and $\mathrm{T} 3$, using logistic regression analyses. To establish whether there are differences in time to reach effective bowel management between the groups, longitudinal regression techniques will be performed. In addition to the analyses of the composite measure of effective bowel management, regression analyses will be performed for the separate variables of faecal incontinence and obstipation.

Whether people with SCI who take antibiotics supplemented with multispecies probiotics have less nausea and a higher QoL compared with people with SCI who take antibiotics supplemented with a placebo will be examined using linear regression analyses. The four aspects of QoL, general QoL, physical health and psychological health are analysed separately. Results of the regression analyses will be presented as Odds ratios or regression coefficients, respectively, $95 \% \mathrm{CI}$, and $p$ values.

\section{Ethics and dissemination}

\section{Ethics}

The study design is described according to the Consolidated Standards of Reporting Trials (CONSORT statement) and SPIRIT 2013 checklist. Approval of the study has been obtained from the Medical Ethics Committee of Amsterdam UMC, location VUmc, Amsterdam, the Netherlands (approval number: 2016.229, A2018.217). The trial is registered in the Dutch Trial Register (NTR 5831; http://www.trialregister.nl/trialreg/index.asp). We certify that all applicable institutional and governmental regulations concerning the ethical use of human volunteers will be followed during this research. 


\section{Dissemination}

The results of the study will be spread via presentations at congresses and publication of peer reviewed articles.

\section{Summary}

Neurogenic bowel dysfunction is one of the most disabling impairments caused by SCI and achieving effective bowel management is a lifelong challenge. Also, people with SCI are at risk of developing infections that require antibiotic treatment and therefore at risk of developing AAD. AAD might negatively influence the rehabilitation process and might also decrease QoL. Multispecies probiotics have proven to be beneficial in preventing AAD in people with various diagnoses. However, trials on the effect of multispecies probiotics in people with SCI are scarce. When completed, this study will be the first randomised placebocontrolled trial on preventing AAD in people with SCI. As such, our study is of great importance. There is much to gain and our results might contribute to the care of people with SCI.

Funding Funding for this study will be provided by the research department of Heliomare. Winclove Probiotics B.V. supplied the probiotics and placebo products. Winclove Probiotics B.V. will not have any say in the analyses, interpretation or how the final paper is written. The results will be written up regardless of the findings.

Author contributions $\mathrm{WF}, \mathrm{JN}$ and $\mathrm{CvB}$ designed the protocol, drafted and/or revised the paper, approved the final version and agreed to be accountable for all aspects of the work in ensuring that questions related to the accuracy or integrity of any part of the work are appropriately investigated and resolved. They will play an important role in acquiring data and/or interpreting the results. $\mathrm{CK}$ and $\mathrm{IBvdV}$, did play a supportive role in the conceptualisation and methodology of the study or the review of the paper. They will not have a role in data collection, data analysis or decision to publish. CK and IBvdV approved the final version of the paper and agreed to be accountable for all aspects of the work in ensuring that questions related to the accuracy or integrity of any part of the work are appropriately investigated and resolved. WAW and JSS drafted and revised the paper, approved the final version and agreed to be accountable for all aspects of the work in ensuring that questions related to the accuracy or integrity of any part of the work are appropriately investigated and resolved. WAW and JSS will play an important role in acquiring data and/or interpreting the results.

\section{Compliance with ethical standards}

Conflict of interest The authors declare that they have no conflict of interest.

Publisher's note Springer Nature remains neutral with regard to jurisdictional claims in published maps and institutional affiliations.

\section{References}

1. Krassioukov A, Eng JJ, Claxton G, Sakakibara BM, Shum S. Neurogenic bowel management after spinal cord injury: a systematic review of the evidence. Spinal Cord. 2010;48:718-33.

2. Coggrave M, Norton C, Wilson-Barnett J. Management of neurogenic bowel dysfunction in the community after spinal cord injury: a postal survey in the United Kingdom. Spinal Cord. 2009;47:323-30.

3. Warms CCDD. Bowel and bladder function and management. In: Field-Fote EC, editor. Spinal cord injury rehabilitation. Philadelphia: F.A. Davis Company; 2009.

4. Lynch AC, Antony A, Dobbs BR, Frizelle FA. Bowel dysfunction following spinal cord injury. Spinal Cord. 2001;39:193-203.

5. Rabadi MH, Mayanna SK, Vincent AS. Predictors of mortality in veterans with traumatic spinal cord injury. Spinal Cord. 2013;51:784-8.

6. Bonfill X, Rigau D, Jauregui-Abrisqueta ML, Barrera Chacon JM, de la Barrera SS, Aleman-Sanchez CM, et al. A randomized controlled trial to assess the efficacy and cost-effectiveness of urinary catheters with silver alloy coating in spinal cord injured patients: trial protocol. BMC Urol. 2013;13:38.

7. Marin J, Nixon J, Gorecki C. A systematic review of risk factors for the development and recurrence of pressure ulcers in people with spinal cord injuries. Spinal Cord. 2013;51:522-7.

8. McFarland LV. Antibiotic-associated diarrhea: epidemiology, trends and treatment. Future Microbiol. 2008;3:563-78.

9. Wong S, Jamous A, O’Driscoll J, Sekhar R, Weldon M, Yau CY, et al. A Lactobacillus casei Shirota probiotic drink reduces antibiotic-associated diarrhoea in patients with spinal cord injuries: a randomised controlled trial. Br J Nutr. 2014;111:672-8.

10. O'Donnell LJ, Virjee J, Heaton KW. Detection of pseudodiarrhoea by simple clinical assessment of intestinal transit rate. BMJ. 1990;300:439-40.

11. Lukasik J, Szajewska H. Effect of a multispecies probiotic on reducing the incidence of antibiotic-associated diarrhoea in children: a protocol for a randomised controlled trial. BMJ Open. 2018;8:e021214

12. Wong S, Santullo P, O'Driscoll J, Jamous A, Hirani SP, Saif M. Use of antibiotic and prevalence of antibiotic-associated diarrhoea in-patients with spinal cord injuries: a UK national spinal injury centre experience. Spinal Cord. 2017;55:583-7.

13. Stiens SA, Bergman SB, Goetz LL. Neurogenic bowel dysfunction after spinal cord injury: clinical evaluation and rehabilitative management. Arch Phys Med Rehabil. 1997;78:S86-102.

14. Sweet SN, Martin Ginis KA, Tomasone JR. Investigating intermediary variables in the physical activity and quality of life relationship in persons with spinal cord injury. Health Psychol. 2013;32:877-85.

15. Hempel S, Newberry SJ, Maher AR, Wang Z, Miles JN, Shanman $\mathrm{R}$, et al. Probiotics for the prevention and treatment of antibioticassociated diarrhea: a systematic review and meta-analysis. JAMA. 2012;307:1959-69.

16. Goldenberg JZ, Lytvyn L, Steurich J, Parkin P, Mahant S, Johnston BC. Probiotics for the prevention of pediatric antibiotic-associated diarrhea. Cochrane Database Syst Rev. 2015;12:CD004827.

17. Wong S, Jamous A, O'Driscoll J, Sekhar R, Saif M, O'Driscoll $\mathrm{S}$, et al. Effectiveness of probiotic in preventing and treating antibiotic-associated diarrhoea and/or Clostridium difficile-associated diarrhoea in patients with spinal cord injury: a protocol of systematic review of randomised controlled trials. Syst Rev. 2015;4:170.

18. Koning CJ, Jonkers DM, Stobberingh EE, Mulder L, Rombouts FM, Stockbrugger RW. The effect of a multispecies probiotic on 
the intestinal microbiota and bowel movements in healthy volunteers taking the antibiotic amoxycillin. Am J Gastroenterol. 2008;103:178-89.

19. Lang FC. Use of a multispecies probiotic for the prevention of antibiotic associated diarrhea. Natrufoods. 2010;9:27-31.

20. Koning CJM. Multispecies probiotic and antibiotic-associated side effects. Pathophysiological and clinical evidence. Maastricht: Maastricht University; 2010.

21. Koning CJMJ DMAE, Stobberingh EE, et al. Effect of a multispecies probiotic on the composition of the dominant faecal flora in healthy volunteers. Gut. 2005;54:A243.

22. Timmerman HM, Niers LE, Ridwan BU, Koning CJ, Mulder L, Akkermans LM, et al. Design of a multispecies probiotic mixture to prevent infectious complications in critically ill patients. Clin Nutr. 2007;26:450-9.

23. Brugger SD, Baumberger C, Jost M, Jenni W, Brugger U, Muhlemann K. Automated counting of bacterial colony forming units on agar plates. PLoS ONE. 2012;7:e33695.

24. Lewis SJ, Heaton KW. Stool form scale as a useful guide to intestinal transit time. Scand J Gastroenterol. 1997; 32:920-4.
25. Nachtegaal J, van Langeveld SA, Slootman H, Post MWM. Implementation of a standardized dataset for collecting information on patients with spinal cord injury. Top Spinal Cord Inj Rehabil. 2018;24:133-40.

26. Post MW, Adriaansen JJ, Charlifue S, Biering-Sorensen F, van Asbeck FW. Good validity of the international spinal cord injury quality of life basic data set. Spinal Cord. 2016;54:314-8.

27. Juul T, Bazzocchi G, Coggrave M, Johannesen IL, Hansen RB, Thiyagarajan $\mathrm{C}$, et al. Reliability of the international spinal cord injury bowel function basic and extended data sets. Spinal Cord. 2011;49:886-91.

28. Meek R, Kelly AM, Hu XF. Use of the visual analog scale to rate and monitor severity of nausea in the emergency department. Acad Emerg Med. 2009;16:1304-10.

29. Kirshblum SC, Burns SP, Biering-Sorensen F, Donovan W, Graves DE, Jha A, et al. International standards for neurological classification of spinal cord injury (revised 2011). J Spinal Cord Med. 2011;34:535-46.

30. Hoffer MM, Feiwell E, Perry R, Perry J, Bonnett C. Functional ambulation in patients with myelomeningocele. J Bone Jt Surg Am. 1973;55:137-48. 